\title{
Convergence in the Spanish and Portuguese NUTSIII regions: an exploratory spatial approach
}

\begin{abstract}
The countries of the Iberian Peninsula both joined the European Union in 1986. Since their membership, both Portugal and Spain have benefited from strong financial support, exhibiting an impressive economic growth and converging to the EU average. However, several authors remain sceptical about persistent regional asymmetries.

That fact, together with deep historical and political bonds and intense economic and trade relationships, motivated us to proceed with an empirical exercise of convergence on the NUTSIII regions of the Iberian Peninsula between 1995 and 2008, using a spatial econometric framework.

At the global scale, our results point to a sigma-divergence process, while, at the national level, we observe a reduction in internal disparities. This apparent contradiction reveals a worrying divergent process between Spain and Portugal (from 2000 onwards). Moreover, our beta-convergence estimations at the Iberian Peninsula scale exclude any catching-up effects among the poorest regions and detect the presence of strong spatial effects, confirming the existence of economic clustering.

We also find some qualitative differences between Spain and Portugal. For the Spanish regions we found a small and non-significant beta-convergence (revealing absence of convergence towards the national average during the period) with strong spatial dependence in the error term. While for the Portuguese regions there was a slow, but significant beta convergence process, without spatial dependence. The difference in these outcomes raises multiple issues namely about the Structural Funds received, leading to further investigation.
\end{abstract}

JEL Classification: C51, R11, R15.

Keywords: agglomeration, convergence, Spanish and Portuguese NUTSIII regions, spatial autocorrelation.

\section{Introduction}

Over the last decades (and especially after WWII) economies have been experiencing mixed performances regarding economic growth, thus motivating economists to study convergence. While some economies have been improving their income levels, others have become progressively poorer at a worldwide scale, thus widening income gaps and deepening disparities.

Despite the large literature dealing with the topics of economic growth and convergence, we emphasize the neoclassical perspective following Solow's ${ }^{1}$ long-run growth model. According to that formulation, countries with an initially lower capital stock grow faster in an earlier stage, converging with the others in the long-term. The explanation lays in the decreasing marginal returns to capital, implying that the lower the stock of capital, the higher the corresponding marginal productivity. 
Therefore, the further an economy is from the steady-state, the faster the rate of growth is, although declining when the economy moves from a low per capita income level to a higher one. At the end of the transitional dynamics, the initially poorer economy reaches the per capita income level of the richer economy (catching up). According to this view, divergence is a transitory short-term phenomenon reflecting adjustments towards a long-run equilibrium level of per capita income. This basic kind of convergence to a common income level, showing an inverse relationship between the initial income level and the corresponding growth rate, is known as absolute (or unconditional) beta-convergence, a term first applied in the early $1990 \mathrm{~s}^{2}$. However, absolute convergence is a strong assumption as it implies that economies possess the same structural parameters (saving rate, population growth, capital depreciation and technology level), differing only in terms of capital endowment. Therefore, it is more probable that such a condition is met for a group of homogenous economies with common institutional and legal features and similar economic parameters. As similarity in terms of common economic policies, higher mobility of factors of production and technological diffusion are more likely observed within national boundaries, it is expected that regions of a given country tend to converge to a certain common steadystate $^{3}$.

Our focus is specifically on regions of the Iberian Peninsula. The first reason is geographical: Portugal and Spain share a common border and it is interesting to analyze the differences between them. Moreover, these countries have been historically engaged, becoming increasingly integrated along the years, having entered the European Economic Community (EEC) in the same year. The countries in question were different in their structural indicators, but both managed to fulfill the nominal targets and be at the forefront of the Economic and Monetary Union (EMU).

Most of Portuguese and Spanish regions where, by the time of the adhesion to the EEC, Objective 1 regions, meaning that their per capita GDP was less than $75 \%$ of the Community average level and thus they were eligible to receive Structural Funds from the EU in order to catch up with the richer nations. As such Portugal and Spain have extensively benefited from EU assistance funds. For instance during the period 19881998, Spain received 22.25 per cent, and Portugal received 11.11 per cent of the total amount of structural funds allocated to all European countries. ${ }^{4}$ As for the Cohesion Fund, Spain received 54.9 per cent of the total money allocated by this fund for the period 1994-1999 and Portugal 18.10 per cent. ${ }^{5}$ During the period between 1995 and 2008, through the Delors II Package (1994-1999) and the Agenda 2000 (2000-2006), Portugal and Spain received together about 140 billion of Euros (at current prices, including Structural and Cohesion Funds).

These monetary supports have been at the core of a wide debate on the efficiency of Structural Funds, as they were mostly oriented to infrastructures and thus did not result in convergence but rather in concentration of technologically advanced activities in specific points in space. ${ }^{6}$ Qualification of the workforce and human capital improvement were not a real priority. Moreover, given the recent entry of Eastern European countries, it is challenging to observe how these two main receivers of Funds will react to the now smaller allocation of financial amounts.

Both Portugal and Spain have been engaged in evident economic growth since their entrance in the European Union (EU) and in convergence in per capita GDP towards the EU average. Several improvements have been taking place, namely in infrastructures, accompanied by increased public investment. However, the regional disparities continue to be a controversial issue. Several empirical studies on regional convergence have pointed to a significant convergence process across regions in Spain until the late1970s and in Portugal since the 1980s until the mid-nineties ${ }^{7}$. Unfortunately, empirical evidence is not conclusive concerning the last decades. ${ }^{8}$ Sanchez and Roura ${ }^{9}$ state that regional disparities have remained essentially constant 
while Marelli ${ }^{10}$ confirms a slackening, although positive, cross-regional convergence process between 1990 and 2005. Rodriguez-Pose ${ }^{11}$, Rodriguez-Pose and Fratesi ${ }^{12}$ and Costa and Fonseca ${ }^{13}$ analyze the regional disparities since 1989 and find a considerable growth in the standard deviation of both Portuguese and Spanish regions at the NUTSII level. ${ }^{14}$ Finally, Gomis-Porqueras and Garcilazo ${ }^{15}$ suggest for the Iberian Peninsula regions, the existence of agglomeration forces by which assistance funds may exacerbate regional gaps, as some regions, by growing faster, induce a drying-out effect in their neighbourhood. These spill over effects are crucial for any convergence process and motivate the relevance of spatial econometric techniques.

Therefore, considering the spatial continuity of the Iberian Peninsula, together with the similar historical path concerning the EEC entrance, we proceed with an empirical convergence exercise among the NUTSIII regions of the Iberian Peninsula, using a spatial econometric approach as a mean to embody the role of space and geography. Regional economies tend to be more open and more specialized than national ones. As spatial units become smaller, economic specialization increases and spatial dependence becomes more relevant. The convergence literature also pays particular attention to the national effect, according to which each region is closely linked to the respective national economic performance (Lopez-Rodriguez and Faina; ${ }^{16}$ Sanchez and Roura ${ }^{17}$ ). As such we differentiate between Portuguese and Spanish regions, in order to check for the presence of a national convergence club effect. The rest of this paper is organized as follows. In section 2 we describe the analytical framework, namely the convergence processes and the spatial effects. In section 3 we proceed with the exploratory spatial analysis and estimate the convergence process, and some final remarks are made in section 4.

\section{The analytical framework}

The neoclassical growth model is based on Solow's ${ }^{18}$ approach and assumes that in the long-run all economies converge to the same steady-state level of per capita income, growing more rapidly the more distant the economy is initially from the equilibrium level. Whenever a negative and statistically significant relation is found between the initial per capita GDP level and the corresponding growth rate, we can assume to be in the presence of absolute beta-convergence. ${ }^{19}$ The absolute betaconvergence was tested by Baumol ${ }^{20}$ through the following equation:

$\frac{1}{T} \ln \frac{y_{i, T}}{y_{i, 0}}=\alpha+\beta \ln y_{i, 0}+\varepsilon_{i} \quad \varepsilon_{i} \rightarrow$ i.i.d $\left(0, \sigma_{\varepsilon}^{2}\right)$

Where $y_{i, t}$ corresponds to the per capita GDP of region $i$ at time $t, \mathrm{~T}$ is the time interval, $\alpha$ and $\beta$ are the parameters to be estimated and $\varepsilon$ the error term. From the estimation of $\beta$, we obtain the speed of convergence, $\theta=-\frac{\ln (1+T \beta)}{T}$ and the time necessary to reach half of the backwardness (half-life), $\tau=\frac{\ln 2}{\theta} \cdot{ }^{21}$

Another concept of convergence is that of sigma-convergence, which analyses the evolution of income disparities across economies over time, through measures of dispersion like the coefficient of variation (an indicator of relative dispersion, given by the ratio of the standard deviation over the sample mean). A reduction of this indicator means a decrease in dispersion and thus the existence of sigma-convergence. Betaconvergence is a necessary but not a sufficient condition for sigma-convergence to occur. ${ }^{22}$ 
Many convergence studies have been centered in cross-section analyses. However, several criticisms are pointed to these models, mostly related with the existence of multicollinearity, endogeneity, biasedness and the existence of specification errors. These problems may seriously affect the robustness of the convergence coefficient and produce misleading outcomes (Quah, ${ }^{23}$ Evans $^{24}$ and Caselli et al. ${ }^{25}$ ). Moreover, according to Anselin ${ }^{26}$ and LeSage and Pace, ${ }^{27}$ among others, the introduction of the geographical dimension, namely in the presence of spatial autocorrelation, allows not only to capture the spatial effect, but also to improve the estimation and prevision since spatial dependence violates some of the Gauss-Markov assumptions of the OLS estimation (cross-section observations are no longer independent) producing inefficient estimators.

\begin{tabular}{|c|c|c|c|c|c|c|c|}
\hline CODE & NUTSIII & CODE & NUTSIII & CODE & NUTSIII & CODE & NUTSIII \\
\hline ES243 & Zaragoza & ES412 & Burgos & ES617 & Málaga & PT161 & Baixo Vouga \\
\hline ES242 & Teruel & ES418 & Valladolid & ES612 & Cádiz & PT168 & Beira Interior Norte \\
\hline ES241 & Huesca & ES411 & Ávila & ES615 & Huelva & PT166 & Pinhal Interior Sul \\
\hline ES230 & La Rioja & ES419 & Zamora & ES618 & Sevilla & PT163 & Pinhal Litoral \\
\hline ES220 & Navarra & ES416 & Segovia & ES614 & Granada & PT16C & Médio Tejo \\
\hline ES212 & Guipúzcoa & ES432 & Cáceres & ES611 & Almería & PT16B & Oeste \\
\hline ES213 & Vizcaya & ES431 & Badajoz & ES613 & Córdoba & PT162 & Baixo Mondego \\
\hline ES211 & Álava & ES424 & Guadalajara & ES616 & Jaén & PT164 & Pinhal Interior Norte \\
\hline ES300 & Madrid & ES423 & Cuenca & ES620 & Murcia & PT16A & Cova da Beira \\
\hline ES120 & Astúrias & ES422 & Ciudad Real & PT184 & Baixo Alentejo & PT169 & Beira Interior Sul \\
\hline ES130 & Cantabria & ES421 & Albacete & PT182 & Alto Alentejo & PT114 & Grande Porto \\
\hline ES112 & Lugo & ES425 & Toledo & PT183 & Alentejo Central & PT117 & Douro \\
\hline ES114 & Pontevedra & ES514 & Tarragona & PT185 & Lezíria do Tejo & PT111 & Minho-Lima \\
\hline ES111 & A Coruña & ES513 & Lleida & PT181 & Alentejo Litoral & PT118 & Alto Trás-os-Montes \\
\hline ES113 & Ourense & ES512 & Girona & PT150 & Algarve & PT116 & Entre Douro e Vouga \\
\hline ES413 & León & ES511 & Barcelona & PT171 & Grande Lisboa & PT112 & Cávado \\
\hline ES414 & Palencia & ES522 & Castellón/Castelló & PT172 & Península de Setúbal & PT113 & Ave \\
\hline ES417 & Soria & ES523 & Valencia/València & PT167 & Serra da Estrela & PT115 & Tâmega \\
\hline ES415 & Salamanca & ES521 & Alicante/Alacant & PT165 & Dão-Lafões & & \\
\hline
\end{tabular}

Table 1: Iberian Peninsula regions (NUTSIII).

Several studies have appeared in the literature, focusing on the importance of spatial location for growth, arguing that when spatial correlation is ignored the results regarding economic growth may be biased. Two kinds of spatial effects are pointed out in the literature, namely: (i) spatial autocorrelation, revealing that contiguous regions may influence each other's performance through spillover effects and (ii) spatial heterogeneity, whenever the same functional form is erroneously considered for all regions. ${ }^{28}$ Spatial autocorrelation, in turn, can be of two types: the spatial autoregressive dependence, in which the dependence is attached to contiguous economic variables and the spatial autocorrelation in the disturbance term, in which the spatial dependence is captured in the error term due to omitted variables or deficient functional form.

For our exploratory spatial analysis we use the per capita GDP at the NUTSIII level between 1995 and 2008, published by the Portuguese and Spanish Official Statistics Offices, deflated by a national GDP deflator (source: AMECO database). We only collect information for regions located in mainland both for Portugal and Spain. Therefore, regions like Azores, Madeira or Canarias are excluded from our analysis as they have not a spatial contiguity with other regions (see Table 1). Summing up, our 
database comprises 75 spatial units, 28 in Portugal and 47 in Spain. After assessing the sigma-convergence, we estimate the presence of spatial autocorrelation, firstly in average per capita GDP, and secondly, on the growth rate between 1995 and 2008, using the Moran's autocorrelation coefficient (Moran's I). Finally we estimate the betaconvergence process. We introduce a national dummy to test the presence of spatial heterogeneity. This specification allows us to estimate the possibility of two different convergence patterns in each country. All estimations are run through the general maximum likelihood method with Matlab. We use the LeSage Spatial Econometrics Toolbox functions available on the Internet at http://www.econ.utoledo.edu, where a comprehensive manual can also be found.

\section{The exploratory spatial data analysis: results and discussion}

Figure 1 illustrates the dispersion, measured by the coefficient of variation of the logarithm of per capita GDP during the 1995-2008 period in the Portuguese and Spanish regions and also for all the 75 regions. Globally, the regional dispersion decreases during the first half period until 2001, and, thereafter, increases reaching an upper level of dispersion relative to the initial point. The Portuguese regional dispersion shows a downward path across the all period while the Spanish coefficient of variation increases a little at first and decreases steadily from 1999 onward, to a lower level relatively to the initial period. Moreover, the Portuguese regional dispersion is steadily above the Spanish one, throughout the period. The apparent contradiction between the global sigma-divergence process and the two national sigma-convergence processes can be explained by a divergence process between the two countries. In fact, Portuguese per capita GDP represented 65\% of the Spanish per capita GDP in 1995, rose to $68 \%$ in 1999 and decreased to $54 \%$ in 2008 .

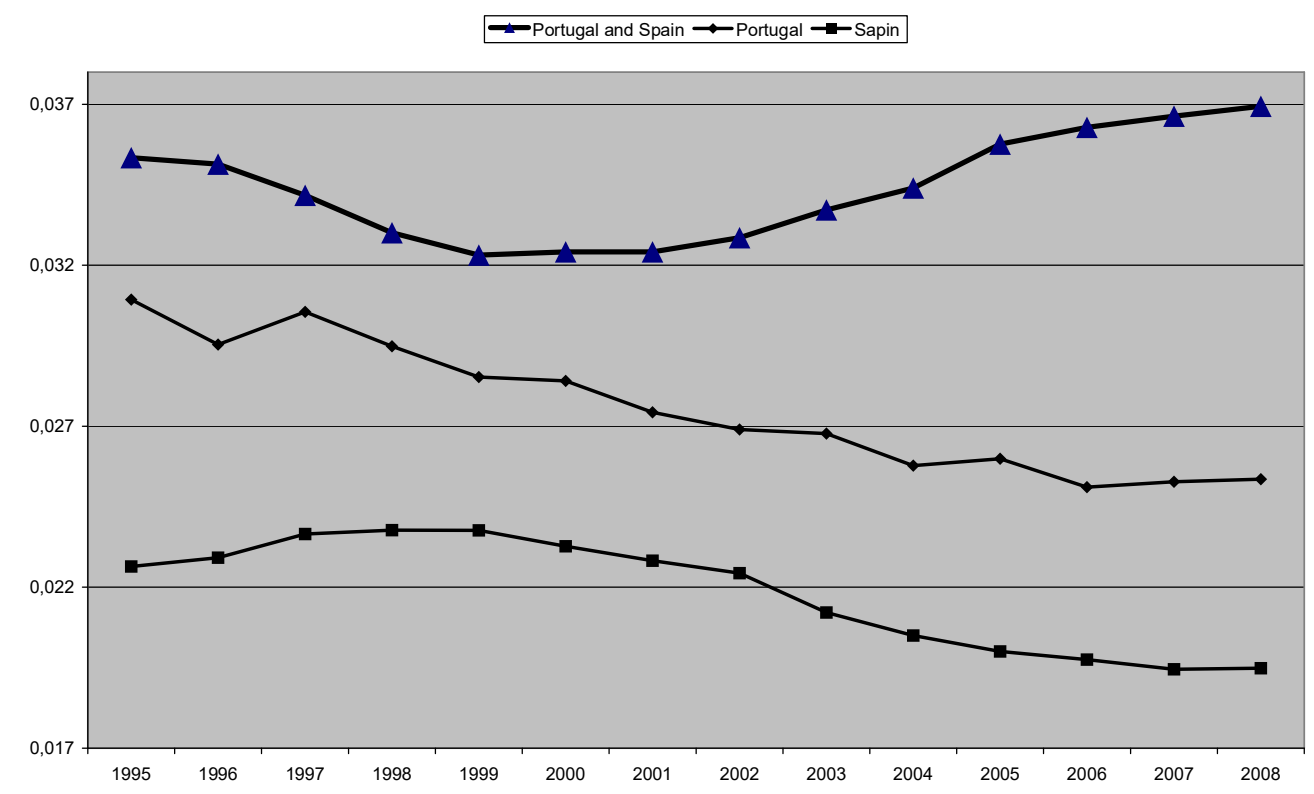

Figure 1: Sigma-convergence between 1995 and 2008. Source: Portuguese and Spanish Official Statistics Offices. 
The spatial autocorrelation is widely measured with the Moran's statistic (Moran's I), which can be represented by the expression:

$$
I_{t}=\frac{n}{\sum_{i=1}^{n} \sum_{j=1}^{n} w_{i j}} \frac{\sum_{i=1}^{n} \sum_{j=1}^{n} w_{i j} x_{i t} x_{j t}}{\sum_{i=1}^{n} \sum_{j=1}^{n} x_{i t} x_{j t}}
$$

in which $\varpi_{i j}$ represents the $\{i, j\}$ element of the spatial contiguity matrix, $\mathrm{W}$, such as $\varpi_{i j}=1$ if municipalities $i$ and $j$ are neighbours and $\varpi_{i j}=0$ otherwise, $x_{i t}$ represents the logarithm of the per capita GDP (in deviation from the mean) of region $i$ at time $t$, and $n$ corresponds to the number of observations.

Moran's I estimates the linear dependence between a variable in a specific location and the mean of the same variable in the neighborhood. The Moran's I-statistic and the respective Marginal Probability relative to the logarithm of per capita GDP are shown in Table 2 revealing a positive and significant spatial dependence in all years and in each scenario (all regions of the Iberian Peninsula and national regions separated). This means that richer regions tend to be located near other rich regions while poor regions tend to aggregate with other poor regions. Moran's I-statistic, concerning all regions (Portuguese and Spanish), shows a similar path relative to the coefficient of variation, decreasing first and increasing from 2000 onwards (the correlation between the Moran's I-statistic and the coefficient of variation is 0.95). This result points that spatial dependence increases with spatial dispersion which may be interpreted as a shadow effect of richer regions over poor ones, leading to a more unequal distribution of the economic activity. Regarding Portugal and Spain, we observe decreasing paths for the whole period, rather similar to the respective coefficient of variation (the correlations are respectively 0.78 and 0.53 ); meanwhile, Spain exhibits a stronger pattern of spatial autocorrelation. ${ }^{29}$

\begin{tabular}{|c|c|c|c|c|c|c|}
\hline & \multicolumn{2}{|c|}{ Portugal and Spain } & \multicolumn{2}{c|}{ Portugal } & \multicolumn{2}{c|}{ Spain } \\
\hline Year & Moran'l & Mg. Prob. & Moran'l & Mg. Prob. & Moran'l & Mg. Prob. \\
\hline 1995 & 0.7277 & 0.0000 & 0.3709 & 0.0002 & 0.6886 & 0.0000 \\
\hline 1996 & 0.7319 & 0.0000 & 0.3554 & 0.0003 & 0.6789 & 0.0000 \\
\hline 1997 & 0.7089 & 0.0000 & 0.3881 & 0.0001 & 0.6690 & 0.0000 \\
\hline 1998 & 0.6914 & 0.0000 & 0.3786 & 0.0001 & 0.6495 & 0.0000 \\
\hline 1999 & 0.6731 & 0.0000 & 0.3423 & 0.0004 & 0.6280 & 0.0000 \\
\hline 2000 & 0.6705 & 0.0000 & 0.3251 & 0.0008 & 0.6239 & 0.0000 \\
\hline 2001 & 0.6890 & 0.0000 & 0.3131 & 0.0011 & 0.6399 & 0.0000 \\
\hline 2002 & 0.7029 & 0.0000 & 0.3198 & 0.0009 & 0.6396 & 0.0000 \\
\hline 2003 & 0.7140 & 0.0000 & 0.3144 & 0.0011 & 0.6355 & 0.0000 \\
\hline 2004 & 0.7290 & 0.0000 & 0.2993 & 0.0018 & 0.6292 & 0.0000 \\
\hline 2005 & 0.7293 & 0.0000 & 0.2774 & 0.0035 & 0.6102 & 0.0000 \\
\hline 2006 & 0.7483 & 0.0000 & 0.3322 & 0.0006 & 0.6129 & 0.0000 \\
\hline 2007 & 0.7581 & 0.0000 & 0.3399 & 0.0005 & 0.6322 & 0.0000 \\
\hline 2008 & 0.7469 & 0.0000 & 0.3025 & 0.0016 & 0.6319 & 0.0000 \\
\hline
\end{tabular}

Table 2: Moran's I statistic.

Figure 2 presents the distribution of the average per capita GDP for the 1995-2008 period across all Iberian regions. The map shows a concentration of rich regions on the Northeast of Spain (the Portuguese Grande Lisboa rich region is the exception), a broad area composed by medium-size income regions in the Center, in the South and 
North of Spain with some Central and Southern Portuguese regions, and a poor area composed by the Northern and inland Portuguese regions.
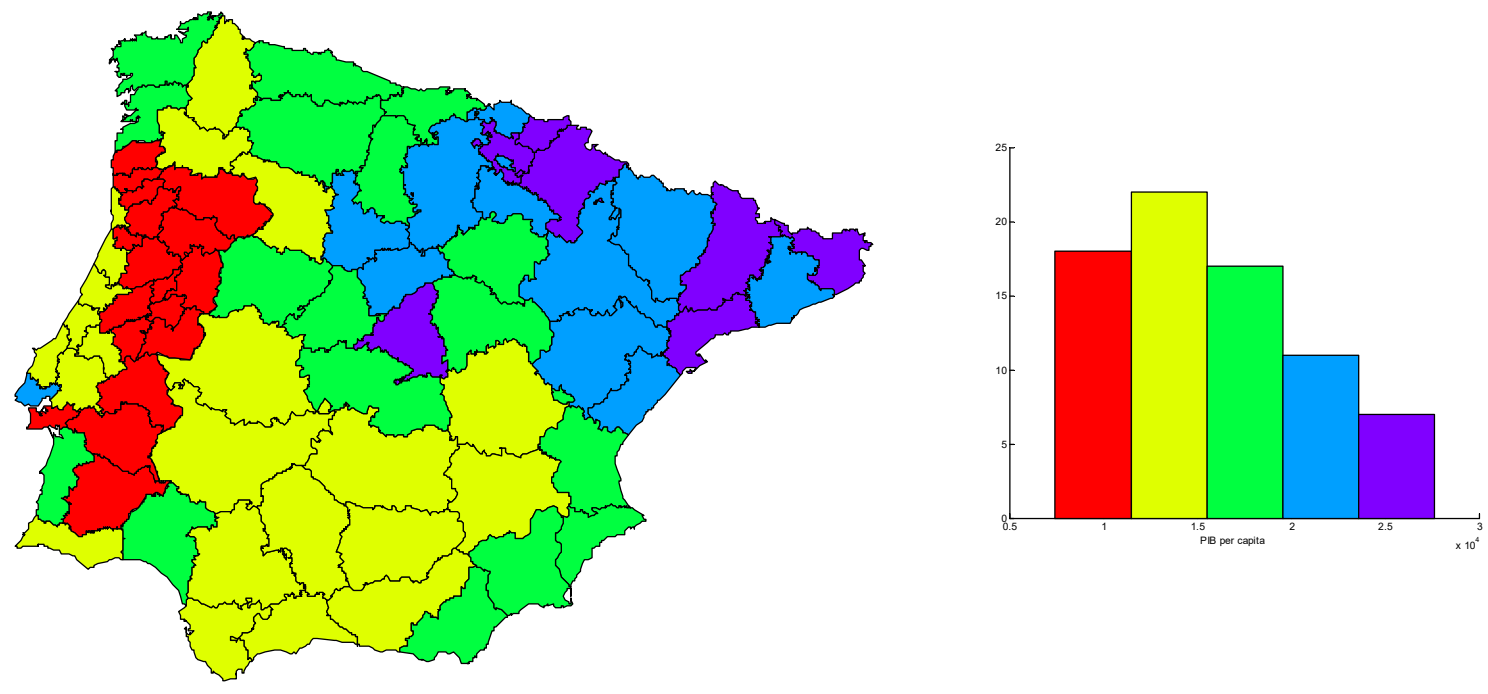

Figure 2: Average per capita GDP 1995-2008, Spanish and Portuguese regions (NUTSIII). Sources: Portugal and Spain Official Statistics.

Figure 3 presents the Moran map and the Moran scatter plot for the same variable. The Moran scatter plot depicts the variable on the horizontal axis with the average values of the neighboring regions for the same variable on the vertical axis. The four quadrants in the scatter plot show, respectively, (i) the regions with high per capita GDP associated with neighboring regions also with high per capita GDP (red points), (ii) the regions with low per capita GDP associated with neighboring regions also with low per capita GDP (cyan points), (iii) the regions with low per capita GDP associated with neighboring regions with high per capita GDP (green points), (iv) the regions with high per capita GDP associated with neighboring regions with low per capita GDP (purple points). The first and second quadrants (high-high and low-low) highlight the existence of positive autocorrelation while the third and fourth ones mean negative autocorrelation. Therefore, the presence of a large number of 61 regions $(81 \%)$ in the first and second quadrants (high-high and low-low) represents a clear symptom of positive spatial autocorrelation. The remaining 14 regions occupy the atypical locations of quadrants three and four. The Moran map depicts the regions using the color coding from the scatter plot. The spatial autocorrelation pattern can be identified by the wide areas with the same color indicating that similar regions tend to aggregate geographically. As such we can see a wide area in red, grouping the rich regions together in the North and East of Spain which contrasts with the South and West of the Iberian Peninsula, including almost all the Portuguese regions. The map also shows some atypical cases of rich regions but without spatial dependence with the neighborhood (La Coruna, Pontevedra, Salamanca, Grande Lisboa among others). 

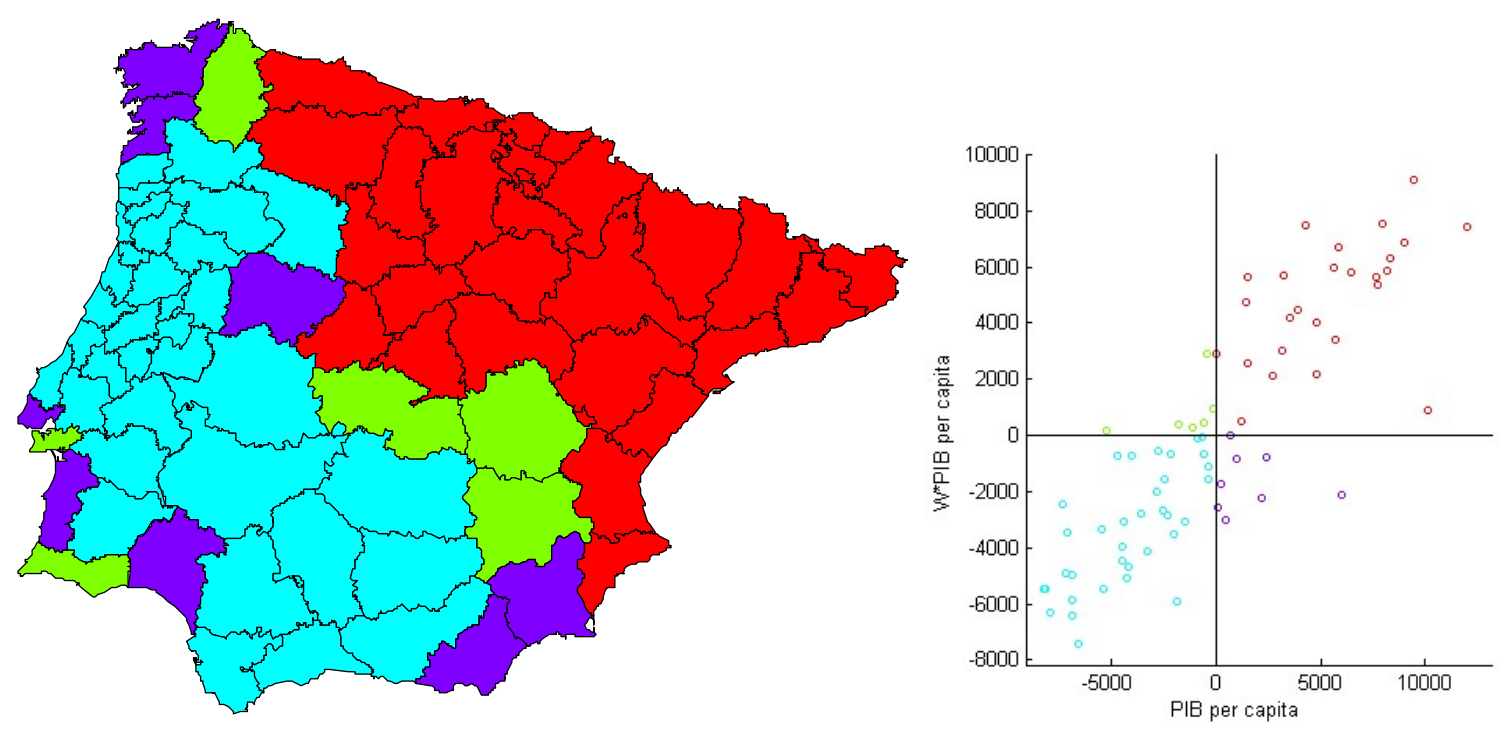

Figure 3: Average per capita GDP 1995-2008, Spanish and Portuguese regions (NUTSIII). Moran map (left-hand side) and Moran scatter plot (right-hand side) (Moran's I = 0.7277).

Concerning the growth rate of per capita GDP between 1995 and 2008 (Figure 4 and 5), the distribution is more heterogeneous across the territory. The highest growth rates belong to Spanish regions, namely Badajoz, Huelva, Cadiz and Almeria in the South, and Vizcaya, Alava, Guipuzcoa, Pontevedra, Asturias, Cantabria, and Zamora in the North. The lowest growth rates correspond to five Portuguese regions: Baixo-Vouga, Ave, Grande Porto, Lezíria do Tejo and Península de Setúbal. The Moran scatter plot shows a concentration of regions in the first and second quadrants (56 regions, equivalent to $75 \%$ of all regions) which is a clear symptom of positive autocorrelation, confirmed by the Moran's I indicator ( 0.44 , with a high level of significance).
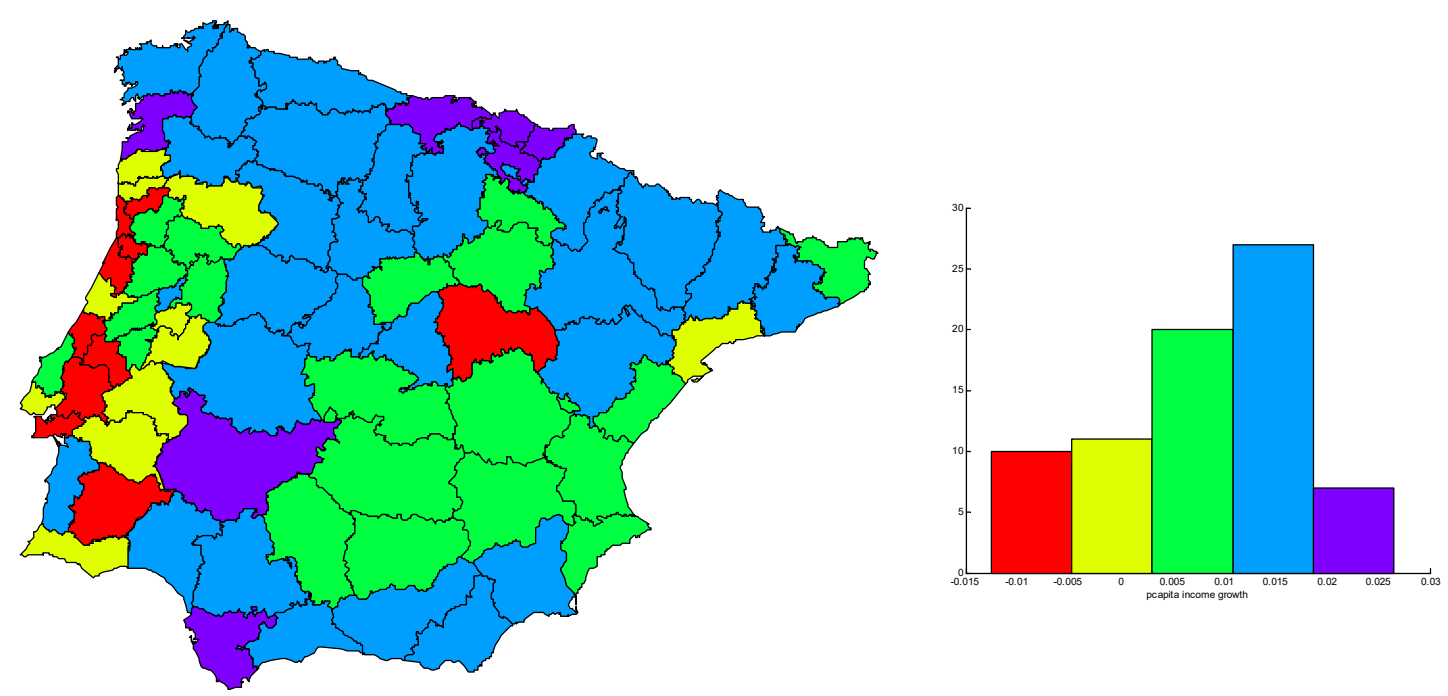

Figure 4: Per capita GDP growth rate 1995-2008, Spanish and Portuguese regions (NUTSIII). Sources: Portugal and Spain Official Statistics. 

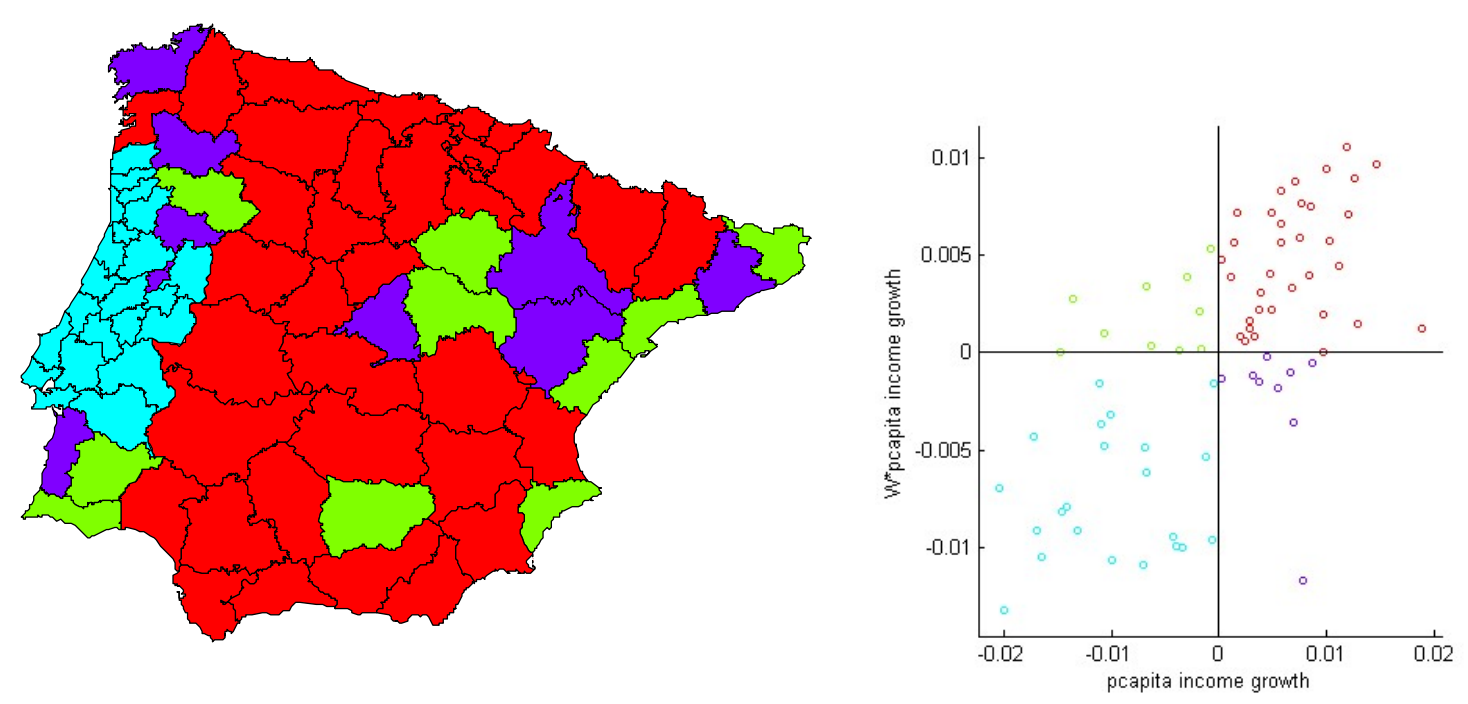

Figure 5: Per capita GDP growth rate 1995-2008, Spanish and Portuguese regions (NUTSIII). Moran map (left-hand side) and Moran scatter plot (right-hand side) (Moran's I= 0.7469).

Finally we use a spatial econometric methodology to estimate a model of absolute beta-convergence for the Iberian NUTS III regions for the 1995-2008 period. First, we estimate the simple model of beta-convergence according to equation (2.1) with and without the national dummy. The next step consists in detecting the presence and type of spatial effects, in order to evaluate whether the spatial lag model or the spatial error model is the most appropriate to describe the data. We follow the robust LM-tests described in Elhorst, ${ }^{30}$ which test for the existence of each kind of spatial dependence. ${ }^{31}$

The results exhibited in the first column of Table 3, concerning all the regions of the Iberian Peninsula, indicate that the specification of the spatial error model in which only disturbances exhibit spatial dependency, given by equation (3.2), is adequate for the convergence process ( $\lambda$ represents the spatial autoregressive parameter in the error term). The results of the three spatial autocorrelation tests can be seen at the bottom of the table: the LM robust error test ${ }^{32}$ indicates the presence of spatial correlation in the residuals of the regression model.

$\frac{1}{T} \ln \frac{y_{i, T}}{y_{i, 0}}=\alpha+\beta \ln y_{i, 0}+u_{i} \quad$ where $u_{i}=\lambda W u_{i}+\varepsilon_{i}$

With the spatial dependence error model (column 2), the slight beta-divergence process estimated by the OLS model ceases to be significant. This excludes the presence of catching-up effects among the poorest regions, as would be predicted according to the sigma-divergence detected above. Therefore, the results, namely the presence of a strong spatial effect, confirm the existence of a polarization of economic activity at the Iberian Peninsula scale.

Columns (3) and (4) of Table 3 present the results for the same equation plus a national dummy variable (Spain), and also indicates the spatial error model (equation (3.3)) as the more adequate. As expected the estimation shows a highly significant dummy coefficient and a slow beta-convergence process (with a velocity of convergence of $1.0 \%$ and a half-life of 69 years), compatible with individual sigma- 
convergence processes in each country, and a significant spatial dependence on the error term. ${ }^{33}$

$\frac{1}{T} \ln \frac{y_{i, T}}{y_{i, 0}}=\alpha+\beta \ln y_{i, 0}+\delta . s p a i n+u_{i} \quad$ where $u_{i}=\lambda W u_{i}+\varepsilon_{i}$

After confirming the spatial heterogeneity in the form of a national effect, we estimate separately the convergence process in the two countries. Concerning the Spanish regions (OLS in column 5 and Spatial Error Model in column 7), the results reveal a very small beta-convergence process, however, non-significant in the Spatial Error Model (with a p-value just above 10\%). The strong spatial dependence in the error term confirms the effect of non-observable variables that may have contributed to the development of contiguous areas, improving (slightly) the income distribution. As for the Portuguese regions (column 6), the OLS estimation reveals a statistically significant beta-convergence process, although, rather slow and without spatial dependence. The velocity of convergence is $1.2 \%$ with a half-life of 58 years.

\begin{tabular}{|c|c|c|c|c|c|c|c|}
\hline Models & $\begin{array}{c}\text { OLS } \\
\text { (ES+PT) } \\
\text { (1) }\end{array}$ & $\begin{array}{c}\text { SEM } \\
\text { (ES+PT) } \\
(2)\end{array}$ & $\begin{array}{c}\text { OLS } \\
\text { (ES+PT) } \\
(3)\end{array}$ & $\begin{array}{c}\text { SEM } \\
\text { (ES+PT) } \\
(4)\end{array}$ & $\begin{array}{c}\text { OLS } \\
\text { (ES) } \\
(5)\end{array}$ & $\begin{array}{c}\text { OLS } \\
\text { (PT) } \\
(6)\end{array}$ & $\begin{array}{c}\text { SEM } \\
\text { (ES) } \\
(7)\end{array}$ \\
\hline \multicolumn{8}{|c|}{ Estimation } \\
\hline Obs & 75 & 75 & 75 & 75 & 47 & 28 & 47 \\
\hline$R^{2}$ & 0.1017 & 0.3875 & 0.5710 & 0.5978 & 0.0682 & 0.1698 & 0.2333 \\
\hline Constant & $\begin{array}{c}0.0025 \\
(0.9283)\end{array}$ & $\begin{array}{c}0.0678 \\
(0.0786)\end{array}$ & $\begin{array}{c}0.1558 \\
(0.0000)\end{array}$ & $\begin{array}{c}0.1621 \\
(0.0000)\end{array}$ & $\begin{array}{c}0.1556 \\
(0.0000)\end{array}$ & $\begin{array}{c}0.1727 \\
(0.0003)\end{array}$ & $\begin{array}{c}0.1636 \\
(0.0005)\end{array}$ \\
\hline$\beta$ & $\begin{array}{c}0.0091 \\
(0.0053)\end{array}$ & $\begin{array}{c}0.0019 \\
(0.6587)\end{array}$ & $\begin{array}{l}-0.0092 \\
(0.0034)\end{array}$ & $\begin{array}{l}-0.0099 \\
(0.0035)\end{array}$ & $\begin{array}{l}-0.0072 \\
(0.0763)\end{array}$ & $\begin{array}{l}-0.0111 \\
(0.0293)\end{array}$ & $\begin{array}{c}-0.0081 \\
(0.1141)\end{array}$ \\
\hline$\delta$ & - & - & $\begin{array}{c}0.0176 \\
(0.0000)\end{array}$ & $\begin{array}{c}0.0182 \\
(0.0000)\end{array}$ & - & - & - \\
\hline$\lambda$ & - & $\begin{array}{c}0.6740 \\
(0.0000)\end{array}$ & - & $\begin{array}{c}0.3180 \\
(0.0549)\end{array}$ & - & - & $\begin{array}{c}0.4930 \\
(0.0046)\end{array}$ \\
\hline \multicolumn{8}{|c|}{ Autocorrelation tests } \\
\hline I Moran & $\begin{array}{c}5.5444 \\
(0.0000)\end{array}$ & - & $\begin{array}{c}2.4788 \\
(0.0132)\end{array}$ & - & $\begin{array}{c}3.6993 \\
(0.0002)\end{array}$ & $\begin{array}{c}0.3302 \\
(0.7413)\end{array}$ & - \\
\hline LM lag (robust) & $\begin{array}{c}0.0196 \\
(0.8890)\end{array}$ & - & $\begin{array}{c}0.4294 \\
(0.5120)\end{array}$ & - & $\begin{array}{c}0.4459 \\
(0.5040)\end{array}$ & $\begin{array}{c}0.0112 \\
(0.9160)\end{array}$ & - \\
\hline LM error (robust) & $\begin{array}{l}19.1410 \\
(0.0000)\end{array}$ & - & $\begin{array}{c}4.3358 \\
(0.0370)\end{array}$ & - & $\begin{array}{l}8.9440 \\
(0.0030)\end{array}$ & $\begin{array}{c}0.0027 \\
(0.9590)\end{array}$ & - \\
\hline
\end{tabular}

Table 3: Estimations results and spatial tests. $\beta$-convergence, 1995-2008 (p-values indicated under parentheses) 


\section{Conclusion}

Using a spatial econometric framework we proceed with an empirical exercise of convergence for the Iberian Peninsula NUTSIII regions between 1995 and 2008, considering the spatial continuity and the historical and political affinity of both countries. The reduction of disparities between the level of development of the various regions and of the backwardness of the least favored regions represents one of the main objectives of the EU, official since the Single European Act in 1987. Portugal and Spain, since their membership, have exhibited an impressive economic growth performance, converging to the EU average. However, several authors remain sceptical about persistent regional asymmetries.

The present empirical exercise involves the period between 1995 and 2008. At the Iberian Peninsula scale, our results point to a sigma-divergence process, while, at the national level, both countries have followed a sigma-convergence process during the same period. This apparent contradiction reveals a worrying divergent process between Spain and Portugal (from 2000 onwards) as well as a strong national effect that has, apparently, precluded some Portuguese border regions from benefiting from the impressive economic growth of some Spanish border regions like Huelva, Badajoz, Zamora or Pontevedra.

We also found some qualitative differences in the convergence pattern between the Spanish and the Portuguese regions. In the former we found a small and nonsignificant beta-convergence with strong spatial dependence in the error term, while in the latter, the estimation reveals a slow, but still significant beta-convergence process, without spatial dependence. This apparent subtle difference means that in the Spanish case, the spatial effects are crucial to the decrease of regional dispersion, while in the Portuguese case, in which spatial effects were not detected, a catching-up process of depressed regions seems to be at the core of the improvement of income distribution. As it can be seen in Figure 4, Spanish regions with high growth rates during this period, like Badajoz, Vizcaya, Pontevedra or Almeria are always surrounded by regions with equal high growth. Differently, the Portuguese regions with the highest growth rates (Alentejo Litoral and Serra da Estrela, two regions who received important public investments) did not seem to have any positive effects on the respective contiguous regions. These results raise multiple issues about the application of Structural Funds and the types of growth they generate leading the way to further investigation.

Integrated in the EU Cohesion Policy, the European Commission (EC) launched, in 1990, a special initiative for border regions known as INTERREG, in order to promote cross-border cooperation (INTERREG-A). Since then, two other INTERREG-A generations have been concluded (1994-1999 and 2000-2006), and another one is on its way, included in the Territorial Cooperation objective (2007-2013). We did not test formally the presence of spatial effects across the border. However, our results confirm a strong national club effect and the incapacity of the Portuguese border regions to capture positive cross border effects from prosperous Spanish regions, which certainly opens other paths for investigation. The inclusion of physical and human capital, population and additional explaining factors is another reasonable line of investigation, to further explore the behavior of NUTSIII regions of the Iberian Peninsula with regard to growth and convergence. Moreover, the adoption of a panel data analysis is also feasible, allowing us to compare results and improve the empirical analysis, gaining degrees of freedom.

\footnotetext{
${ }^{1}$ R. Solow: A contribution to the theory of economic growth, in: Quarterly Journal of Economics, Vol. 70 , No.1, 1956, pp. 65-94.

${ }^{2}$ R. Barro, X. Sala-i-Martin: Economic growth, Cambridge 2004, The MIT Press.

3 X. Sala-i-Martin: Regional cohesion: evidence and theories of regional growth and convergence, in: European Economic Review, Vol. 40, No.6, pp. 1325-1352.
} 
${ }^{4}$ P. Gomis-Porqueras, E. Garcilazo: EU Structural and Cohesion Funds in Spain and Portugal: Is Regional and National Inequality Increasing?, in: Miami European Union Center, Working Paper Series, vol. 3, no.11, 2003.

${ }^{5}$ P. Gomis-Porqueras, E. Garcilazo, op. cit.

${ }^{6}$ For an interesting survey about structural funds and Objective 1 regions see: F. Torres, M. L. de Freitas, F. Pereira: Convergence among EU Regions, 1990-2001 - Quality of National Institutions and "Objective 1" Status, in Intereconomics, Review of European Economic Policy, Volume 38, number 5, 2003, page 270 to 275 .

7 A. Sanchez, T. Roura: Regional convergence in productivity and productive structure. Application to European Southern countries, in: Institute of Social and Economic Analysis, Working paper 11, 2008.

${ }^{8}$ P. Gomis-Porqueras, E. Garcilazo, op. cit.

${ }^{9}$ A. Sanchez, T. Roura, op. cit.

${ }^{10} \mathrm{E}$. Marelli: Specialisation and convergence of European regions, in: The European Journal of Comparative Economics, Vol.4, No.2, 2007, pp. 149-178.

11 A. Rodriguez-Pose: Economic convergence and regional development strategies in Spain: The case of Galicia and Navarre, in: European Investment Bank Papers, Vol.5, No.1, 2000, pp. $89-115$.

12 A. Rodriguez-Pose, U. Fratesi: Between development and social policies: the impact of European Structural Funds in Objective 1 regions, in: Regional Studies, Vol.38, No.1, 2004, pp.97-113.

${ }^{13}$ E. Costa, M. Fonseca, op. cit.

${ }_{14}$ Most of references about empirical studies use the NUTSII regional level.

${ }^{15}$ P. Gomis-Porqueras, E. Garcilazo, op. cit.

$16 \mathrm{~J}$. Lopez-Rodriguez, A. Faina: Regional policy and convergence in Europe: the case of backward regions, in: Economics Bulletin, Vol. 29, No. 2, 2009, pp.1046-1053.

${ }^{17}$ A. Sanchez, T. Roura, op. cit.

${ }^{18}$ R. Solow, op. cit.

${ }^{19}$ R. Barro, X. Sala-i-Martin, op. cit.

${ }^{20} \mathrm{~W}$. Baumol: Productivity growth, convergence and welfare: what the long-run data show?, in: American Economic Review, Vol.76, No.5, 1986, pp.1072-1085.

${ }^{21}$ For details, see N.Islam: Growth empirics: a panel data approach, in: The Quarterly Journal of Economics, Vol.110, No.4, 1995, pp.1127-70 and S.Silva, M. Silva (2000): Crescimento económico nas regiões europeias: Uma avaliação sobre a persistência das disparidades regionais no período 1980-95, in: FEP Working Paper 96, 2000.

${ }^{22}$ M. Chatterii: Convergence clubs and endogenous growth, in: Oxford Review of Economic Policy, Vol.8, No.4, 1992, pp.57-69.

${ }^{23}$ D. Quah: Galton's fallacy and tests of the convergence hypothesis, in: The Scandinavian Journal of Economics, Vol.95, No.4, 1993, pp.427-443.

${ }^{24} \mathrm{P}$. Evans: Using cross-country variances to evaluate growth theories, in: Journal of Economic Dynamics and Control, Vol.20, No.6-7, 1996, pp.1027-1049.

${ }^{25}$ F. Caselli, G. Esquivel, F. Lefort: Reopening the convergence debate: a new look at crosscountry growth empirics, in: Journal of Economic Growth, Vol.1:, No.3, 1996, pp.363-389.

${ }^{26}$ L. Anselin: Spatial econometrics: methods and models, Dordrecht 1988, Kluwer Academic Publishers.

27 J. LeSage, R. Pace: Introduction to spatial econometrics, USA 2009, CRC Press, Taylor and Francis Group.

${ }^{28}$ For comprehensive references about spatial econometric see for instance L.Anselin, op. cit., LeSage and Pace, op. cit., and J. LeGallo: Econometrie spatiale: l'autocorrelation spatial dans les modèles de regression lineaire, in: Economie et Provision, Vol.155, No.4, 2002, pp.139-158.

29 The positive correlation between the Moran's I-statistic and the coefficient of variation can be found in other empirical studies (see, for instance, LeGallo et al., op.cit.). 
$30 \mathrm{~J}$. Elhorst: Specification and estimation of spatial panel data models, in: International Regional Science Review, Vol.26, No.3, 2003, pp.244-268.

${ }^{31}$ Matlab routines available at www.regroningen.nl/elhorst.

$32 \mathrm{~J}$. Elhorst, op. cit.

${ }^{33}$ We also introduced a national dummy variable multiplied by the initial income level in order to detect difference in the convergence rate but the estimation does not detect any statistical significance. 